\title{
Ultrastructural localisation of alkaline phosphatase activity in osteoarthritic human articular cartilage
}

\author{
J A REES AND S Y ALI \\ From the Department of Experimental Pathology, Institute of Orthopaedics (University of London), Royal \\ National Orthopaedic Hospital, Stanmore, Middlesex
}

SUMmaRY The distribution of alkaline phosphatase activity in human articular cartilage from normal and osteoarthritic joints has been examined by an electron microscope technique, probably for the first time. In osteoarthritic cartilage chondrocytes and matrix vesicles close to the tidemark were positive for alkaline phosphatase activity. Large numbers of matrix vesicles were found within the extracellular matrix of osteoarthritic cartilage, and there is a specific relation between phosphatase activity, matrix vesicles, and initial mineral formation in the tidemark region of articular cartilage.

Osteoarthritis may be considered as a group of heterogeneous diseases with a final common pathway involving abnormal changes in some joint tissues and in particular articular cartilage. This 'joint failure' can be initiated by various endogenous processes, and the occurrence of hydroxyapatite and pyrophosphate crystals in joint fluids has led to the concept of crystal deposition arthropathy and apatite associated arthritis. ${ }^{1-3}$ Previous biochemical studies indicated there may be abnormal calcification in human osteoarthritic cartilage as seen by increased amounts of alkaline phosphatase activity. ${ }^{45}$ In addition, detailed electron microscope studies have shown several different types of calcium phosphate crystals in arthritic articular cartilage. ${ }^{6-9}$ These apatite-like crystal types appear to be associated with matrix vesicles, which have been shown in other calcifying tissues to contain most of the alkaline phosphatase activity and to initiate the calcification process. ${ }^{1011}$

Robison initially introduced the idea that alkaline phosphatase enhanced calcification of cartilage, probably by raising the phosphate concentration locally. ${ }^{12}$ Gomori demonstrated histochemically that cartilage calcification occurred only in areas that were rich in alkaline phosphatase. ${ }^{13}$ Since then alkaline phosphatase has been localised in the calcifying regions of bone ${ }^{14}{ }^{15}$ and teeth, ${ }^{16}$ further substantiating Robison's view.

Accepted for publication 19 February 1988.

Correspondence to Professor S Y Ali, Department of Experimental Pathology, Institute of Orthopaedics (University of London), Royal National Orthopaedic Hospital, Brockley Hill, Stanmore, Middlesex HA7 4LP.
At the ultrastructural level alkaline phosphatase has been localised in a number of different calcifying cartilages. The distribution in growth plate has been described by Matsuzawa and Anderson, ${ }^{17}$ Thyberg and Friberg, ${ }^{18}$ Takagi and Toda, ${ }^{19}$ and Ralphs and $\mathrm{Ali}^{20}$; in fracture callus by Gothlin and Ericsson, ${ }^{21}$ Salomon, ${ }^{22}$ and Volpin et $a l^{23}$; and in condylar cartilage by Meikle ${ }^{24}$ and Lewinson et al. ${ }^{25}$ In articular cartilage the enzyme distribution has been studied using a light microscope technique only. ${ }^{26}$ It is intended to extend these observations to the ultrastructural level and look for associations between alkaline phosphatase activity, chondrocytes, matrix vesicles, and initial mineral formation in human osteoarthritic articular cartilage.

\section{Materials and methods}

Fresh human osteoarthritic cartilage was obtained from femoral heads resected for total hip replacement. The cartilage was degenerate, fibrillated cartilage from the pressure bearing, progressive area. It was usually restricted to a fringe surrounding the eburnated bone around the superior surface of the femoral head. This cartilage is usually yellow and found as a sloping or shelving ring adjacent to the circle of eburnated bone (type IV cartilage, see Ali and Bayliss ${ }^{5}$ ). The specimens were obtained from five female patients aged 58,61,63, 69, and 76 years. In the last year it has been impossible to obtain fresh, age matched, normal human articular cartilage. Disease free cartilage was obtained from the femoral heads of two female patients aged 83 and 85 years with subcapital fractures of the neck of 
femur. Small pieces of cartilage were excised down to and including the subchondral bone. Some of the specimens were put into $2.5 \%$ glutaraldehyde in $0.085 \mathrm{M}$ sodium cacodylate buffer and then processed for transmission electron microscopy by standard techniques described elsewhere. ${ }^{5}$

For the visualisation of alkaline phosphatase activity a metal salt method similar to that described by Volpin $e t$ al $^{23}$ was used. Briefly, this consisted of taking very thin tissue slices $(30-200 \mu \mathrm{m}$ thick) through the whole depth of cartilage. These were cut with new razor blades under a dissecting microscope while immersed in $1.5 \%$ glutaraldehyde in $0.085 \mathrm{M}$ sodium cacodylate buffer. After one hour the tissue slices were washed in buffer and immersed in the incubation medium (containing the enzyme substrate $9 \mathrm{mM}$ sodium $\beta$-glycerophosphate, $10 \mathrm{mM}$ magnesium chloride, $3.6 \mathrm{mM}$ lead nitrate, and $40 \mathrm{mM}$ trometamol (TRIS)/HCl buffer at $\mathrm{pH}$ 9) for 30 minutes at $37^{\circ} \mathrm{C}$.

To test for false non-enzymatic deposition of reaction product control tissue slices were incubated in a medium to which $2 \mathrm{mM}$ levamisole had been added as an inhibitor of alkaline phosphatase activity. Further control slices were incubated in a medium which did not contain the enzyme substrate (sodium $\beta$-glycerophosphate). After washing in $0.085 \mathrm{M}$ cacodylate buffer for 10 minutes test and control cartilage slices were postfixed in $1 \%$ osmium tetroxide in cacodylate buffer for one hour. After dehydration through graded ethanols and finally 1:2-epoxypropane the specimens were infiltrated with Araldite resin overnight and polymerised at $60^{\circ} \mathrm{C}$ for 48 hours. For orientation purposes $1 \mu \mathrm{m}$ thick sections were cut for light microscopy with glass knives and stained with Humphrey's stain. Thin sections $(60-80 \mathrm{~nm})$ were cut with diamond knives and collected on parlodion coated copper grids. Sections were examined, unstained or after staining with saturated alcoholic uranyl acetate for 30-45 minutes and lead citrate for five minutes, on a Philips EM300 at $60 \mathrm{kV}$ or $80 \mathrm{kV}$.

\section{Results}

'NORMAL' CARTILAGE FROM SUBCAPITAL FRACTURE SPECIMENS

Light and electron microscope sections showed the cartilage surface was smooth with collagen fibres in the superficial layer arranged parallel to the surface. Chondrocytes were discoidal with their long axes parallel to the cartilage surface. In the mid-zone cartilage chondrocytes were spheroidal and equally spaced or occasionally arranged in columns of four to eight cells. The collagen fibres in the mid-zone matrix were predominantly radial. In the deep zone the calcifying front or tidemark region appears eve or gently undulating by light microscopy or low. power electron microscopy. At higher magnificatio matrix vesicles in the pericellular region of chondrof cytes were present at all levels of the cartilage buf were more frequent in the tidemark region. In the region microcrystals were present inside vesicles: and mineral nodules could be seen either forming from vesicles or lying next to them (Fig. 1). In manक् sections from several blocks of the normal cartilage from subcapital fracture specimens, clusters of chondrocytes were frequently seen in this regiorw but only one cluster was positive for alkalinge phosphatase activity (Figs 1 and 2). This reaction product appeared as a few electron dense beads along the chondrocyte cell membrane (Fig. 20 arrows). This cluster of chondrocytes was only about $40 \mu \mathrm{m}$ from the calcifying front.

Chondrocytes and matrix vesicles further than $40 \mu \mathrm{m}$ from the calcifying front showed no evidence of alkaline phosphatase reaction product in disease free articular cartilage. Lack of penetration of the substrate as a factor indicating lack of enzyme activity could be ruled out because some cartilage slices were only $40-50 \mu \mathrm{m}$ thick and wouldobe penetrated relatively easily by the substrate. Matrio

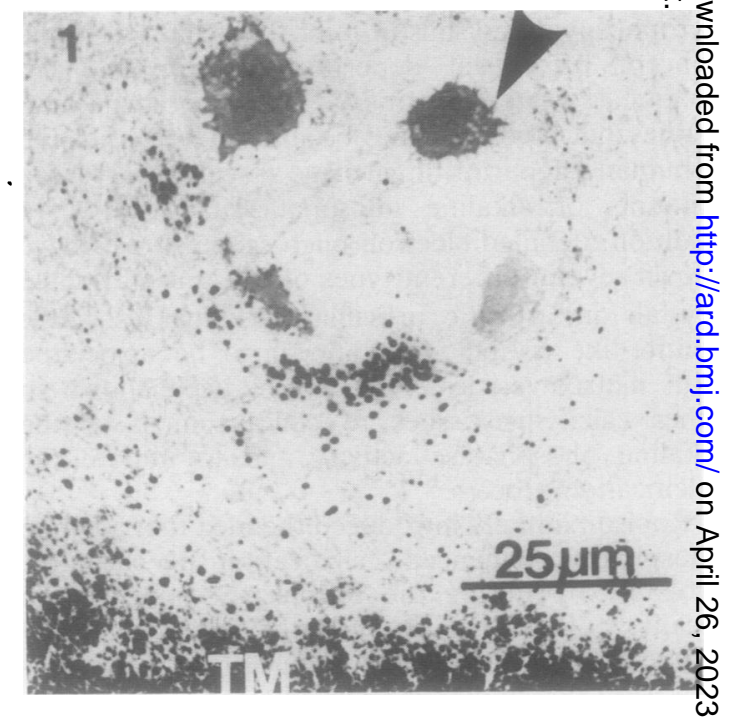

Fig. 1 Lowpower electron micrograph of a section of disea free cartilage (woman, 85 years) incubated for alkaline phosphatase activity. A cluster of partially reactive chondrocytes are seen approximately 40 um from the tidemark (TM). This unstained section shows the distribution of mineral nodules around the cluster of chondrocytes. The chondrocyte indicated by an arrow head is shown enlarged in Fig. 2. 


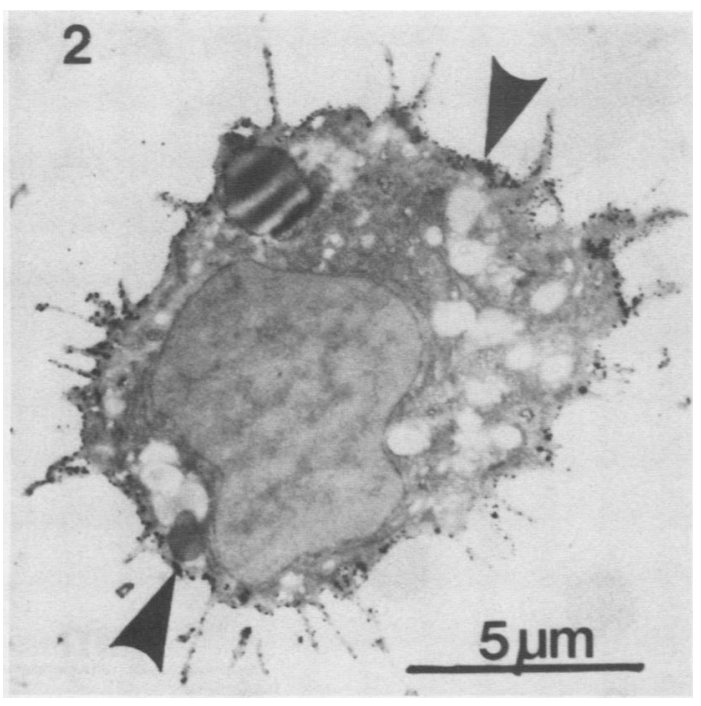

Fig. 2 Higherpowermicrographofachondrocyteseen in Fig. 1. Note electron dense beads of alkaline phosphatase activity reaction product along the cell membrane (arrows). There is no reaction product inside ihe cell. (Unstained section.)

vesicles in disease free, non-osteoarthritic cartilage showed very limited reaction product for alkaline phosphatase compared with the levamisole inhibited controls. Sections of specimens treated with incubation medium containing levamisole, or without an enzyme substrate, showed no reaction product in any region of the cartilage, even around chondrocytes or matrix vesicles less than $40 \mu \mathrm{m}$ from the nearby tidemark region.

OSTEOARTHRITIC CARTILAGE

The cartilage examined showed microscopic evidence of surface fibrillation, loss of matrix staining in the superficial region for proteoglycans, and reduced cellularity. We confirmed an increased number of matrix vesicles in the pericellular area in all the cartilage zones but particularly in the deep zone near the tidemark. The tidemark region was usually irregular, and observations by light microscopy indicated its reduplication in several areas. Electron microscopy indicated increased numbers of matrix vesicles and mineral nodules in this region.

In sections incubated for alkaline phosphatase activity there was little evidence of electron dense precipitate around chondrocytes in either the superficial or mid-zone cartilage. In contrast, in all the osteoarthritic specimens studied several chondrocytes in the deep zone (up to $150 \mu \mathrm{m}$ from the tidemark region) reacted strongly for alkaline phos- phatase activity (Figs 3-6). In some cases the reaction was strong enough to be observed by light microscopy. In the electron microscope this reaction appeared as an electron dense precipitate along the

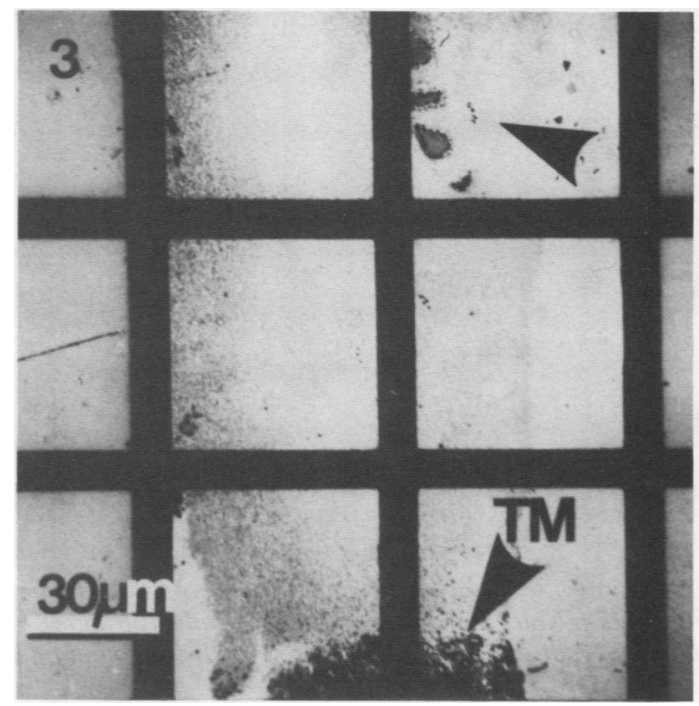

Fig. 3 Low power electron micrograph of osteoarthritic cartilage incubated for alkaline phosphatase activity (woman. 76 years). Note a cluster of reactive chondrocytes (arrow) about $150 \mu \mathrm{m}$ from the tidemark (TM). (Unstained section.)

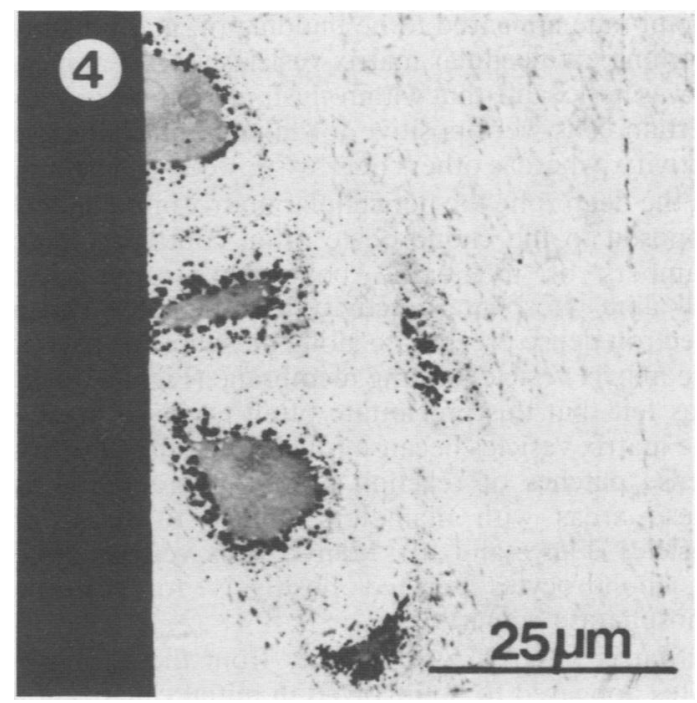

Fig. 4 Higherpowermicrographof the cluster of chondrocytes seen in Fig. 3. Note dense precipitate around the cell membranes and matrix vesicles within the extracellular matrix, positive for alkaline phosphatase activity. (Unstained section.) 

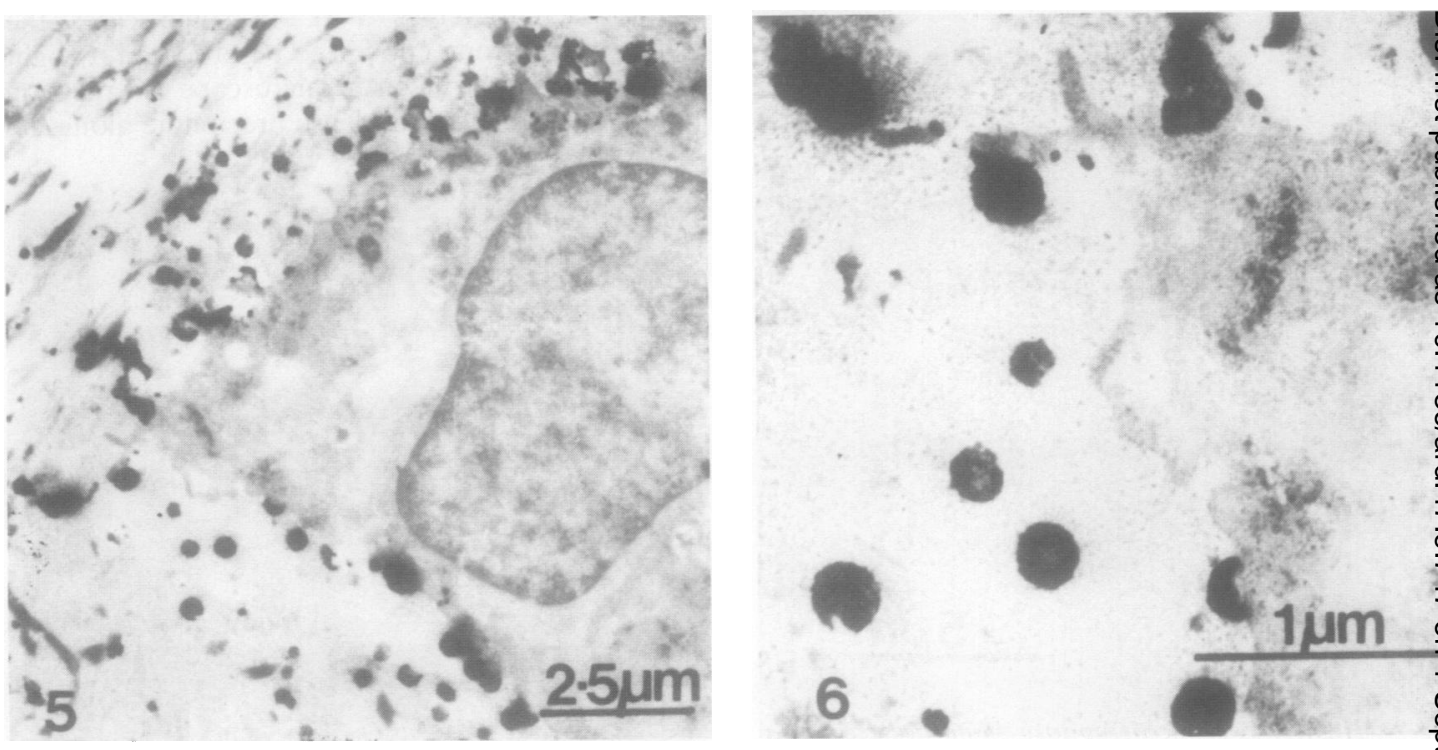

Figs 5 and 6 Serial section to that seen in Figs 2 and 3. Higherpowermicrographs of cell membrane of chondrocyte seen in Figs 3 and 4. Note electron dense reaction product on the cell membrane (Fig. 4). There is some evidence that these portions of th cell membrane may be 'budding off' into the surrounding matrix. forming matrix vesicles (Fig. 6). (Stained section.)

cell membrane of the chondrocytes (Fig. 4). There was considerable variation in the intensity of reaction product found around chondrocytes in the deep zone. In some instances reactive portions of the cell membrane appeared to be budding off and possibly forming extracellular matrix vesicles (Figs 5 and 6). It was noticeable that within clusters of chondrocytes certain cells were positive for alkaline phosphatase activity, whereas others nearby showed no reaction. In the deep zone the pericellular matrix immediately apposed to the chondrocyte often contained large numbers of membrane bound matrix vesicles. Alkaline phosphatase activity was indicated by an electron dense precipitate along the whole or part of the matrix vesicle limiting membrane (Figs 7-10). It was felt that this precipitate often totally obscured the matrix vesicles because roughly circular electron dense patches of reaction product were found in these areas with diameters similar to those of vesicles (Figs 6 and 10). Many matrix vesicles close to chondrocytes reacted positively for alkaline phosphatase activity.

Matrix vesicles further away from the chondrocytes appeared to be involved in initial calcification of the extracellular matrix in the tidemark region by progressive deposition of needle like crystals of hydroxyapatite in and around matrix vesicles. These vesicles showed evidence of alkaline phosphatase activity (Fig. 9). As mineral accumulation appeared to progress most of the extracellular matrix bec calcified and alkaline phosphatase activity reaction product could not be differentiated clearly fro calcific deposits.

Control sections, either treated with incubatio medium containing levamisole or with the enzyna substrate omitted, showed negligible reactivity for alkaline phosphatase, even around chondrocyt and matrix vesicles in the tidemark region of the cartilage 150 um from the calcifying front (Fig. 11 .

\section{Discussion}

We studied the distribution of alkaline phosphatase activity in human articular cartilage from ostesarthritic joints by an electron microscope technique and compared it with two normal subcapital fracture specimens. Normal cartilage showed little or reaction in any region, either around chondrocyt $\tilde{O s}$ or matrix vesicles. In one specimen a cluster of chondrocytes very close to the calcifying fron ( $40 \mu \mathrm{m}$ away) showed a limited amount of reaction In contrast, in degenerative cartilage from patients. with osteoarthritis of the hip several chondrocytes 9 m the deep zone were always positive for alkalipe phosphatase activity. Furthermore, large numbefs of matrix vesicles were found within the extracellulor $r$ matrix, and there is a specific relation betwe alkaline phosphatase activity. matrix vesicles, a ad 
initial mineral formation in the deep zone as demonstrated by this technique. In this study we were unable to obtain any age matched, normal

fresh specimens to provide a direct comparison with the osteoarthritic group. Here we were forced to be content with normal subcapital fracture specimens
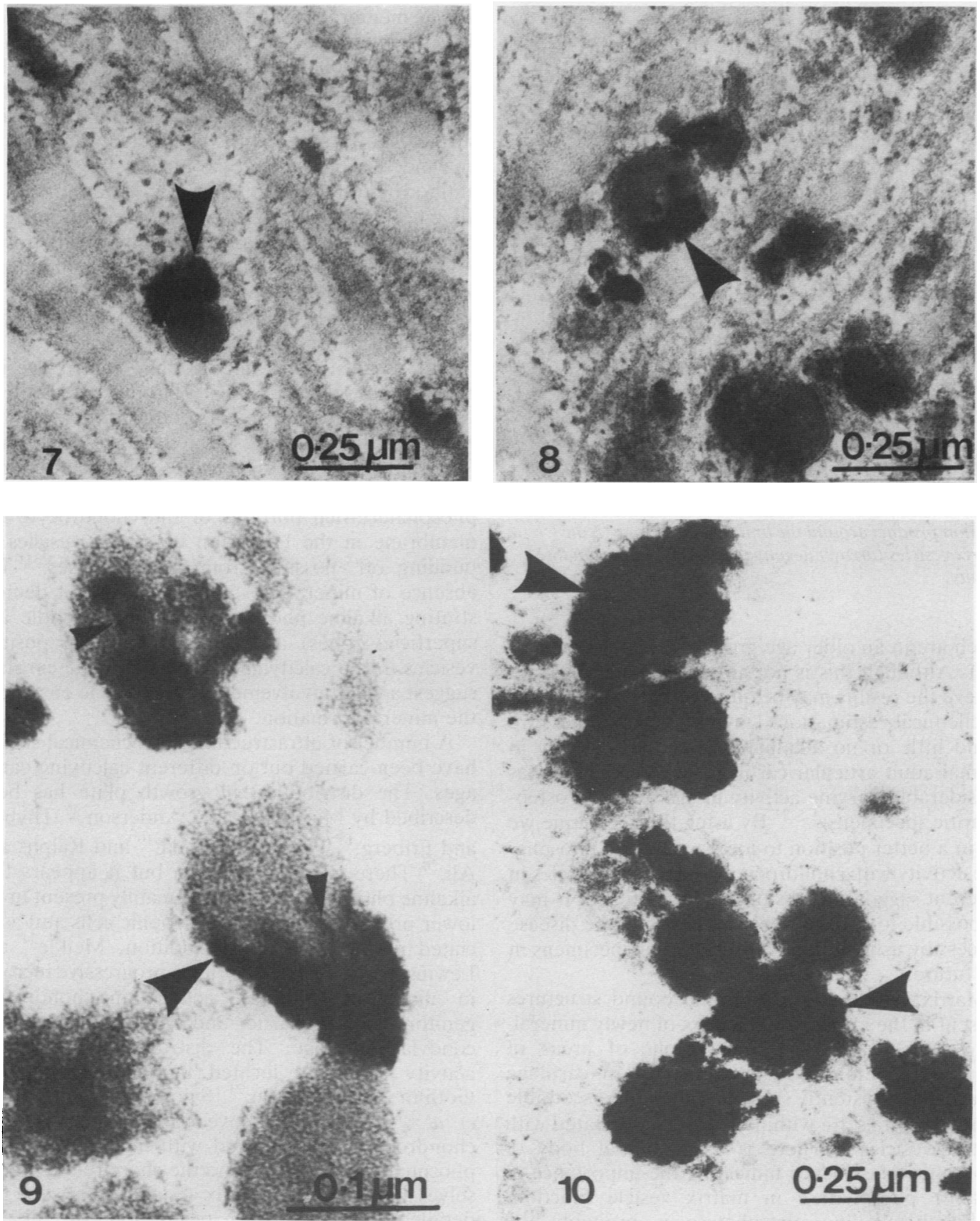

Figs 7-10 High power micrographs of matrix vesicles in the extracellularmatrix in the deep zone of osteoarthritic cartilage incubated for alkaline phosphatase activity. Note alkaline phosphatase activity reaction products (arrows) and initial crystals of hydroxyapatite (small arrows). (Stained sections.) 


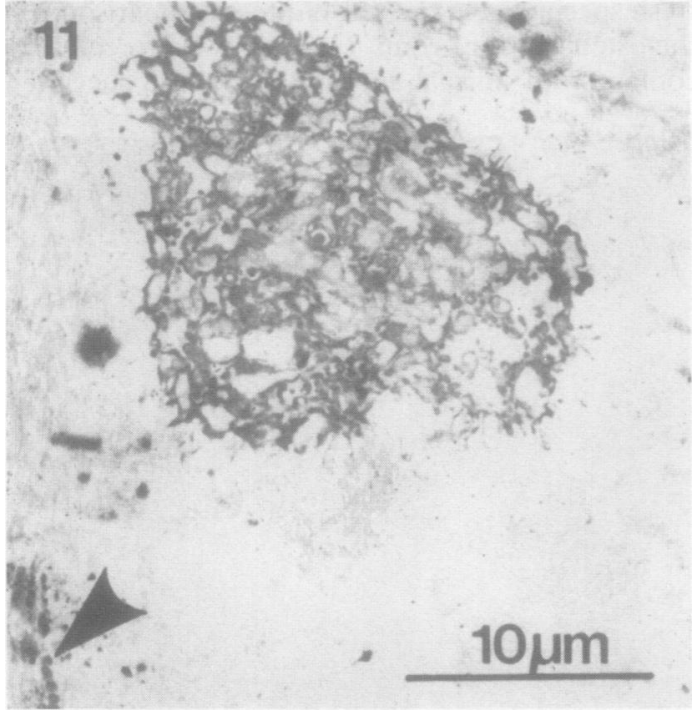

Fig. 11 Control section (with the specific inhibitor of alkaline phosphatase, levamisole, in the incubation medium). Osteoarthritic articular cartilage (woman. 76 years).

A chondrocyte less than 100 um from the tidemark shows no reaction product around the limiting membrane. Note matrix vesicles (arrow) negative for alkaline phosphatase activity.

which are in an older age group (83 and 85 years of age). Although this is not an ideal comparison, we believe the results may be quite valid because in our biochemical estimations in previous studies we found little or no alkaline phosphatase activity in normal adult articular cartilage, whereas there was considerable enzyme activity in age matched osteoarthritic specimens. ${ }^{+527}$ By using this technique we are in a better position to localise alkaline phosphatase activity with chondrocytes and matrix vesicles in different saggital depths of human cartilage. It may be possible to correlate this activity with the disease process by using a number of different specimens in the future.

Matrix vesicles are membrane bound structures present in the extracellular matrix of newly mineralising tissues. Electron micrographs of areas of incipient mineralisation in a number of cartilage tissues all consistently show that the first discernible mineral crystals are within or closely associated with matrix vesicles. ${ }^{10}$ There is a substantial body of experimental evidence indicating the importance of alkaline phosphatase in matrix vesicle function. Although alkaline phosphatase is probably the major enzyme activity in matrix vesicles, its role in initial mineralisation is by no means clear cut and a number of possible roles for this enzyme have been suggested. The subject of matrix vesicle mediate mineralisation has been reviewed by Ali, Anderson. ${ }^{28}$ and Wuthier. ${ }^{29}$ Cytochemical andmorphological evidence implicates the matrix vesicle membrane as the site of initial mineralisation? This site may represent a logical position to regulate a flux of phosphate ions across matrix vesicles. Th lead phosphate reaction product produced by this technique, which is localised at the matrix vesiclon surface, may not reflect the complete location of the enzyme. ${ }^{30}$ More reliable would be the use of ait antibody to recognise antigenic determinants of alkaline phosphatase rather than the present tech nique which localises enzyme activity. In the future it is hoped to use an electron microscope immunot localisation technique on sections of articular cartike age to establish further the exact location an function of phosphatase enzymes.

Our results have shown that matrix vesicle alkaline phosphatase activity is only detectable in vesicles in the deep zone of osteoarthritic cartilagen where positive cells are located, suggesting vesicle formation from cell membrane. Evidence obtaine $\Phi$ in this study (Figs 5 and 6) implicates alkalin@ phosphatase-rich portions of the chondrocyte celt membrane in the formation of matrix vesiclesक्वेळ budding off, possibly from cell processes. ${ }^{31}$ 勇e absence of mineral crystals in vesicles not demono strating alkaline phosphatase activity (middle an superficial zones) and their presence in positive vesicles in the calcifying deep zone of the cartilage suggest a clear involvement of the vesicle enzyme is the mineral formation.

A number of ultrastructural histochemical studie have been carried out on different calcifying cartie ages. The distribution in growth plate has beer. described by Matsuzawa and Anderson, ${ }^{17}$ Thyberm and Friberg, ${ }^{18}$ Takagi and Toda, ${ }^{19}$ and Ralphs an 8 Ali. ${ }^{20}$ There is some variation but it appears tha alkaline phosphatase activity is mainly present in the lower proliferative and hypertrophic cells and assos ciated matrix vesicles. In addition, Meikle ${ }^{24}$ and Lewinson et $a l^{25}$ have reported a progressive increas in alkaline phosphatase activity in chondroproo genitor, chondroblastic, and hypertrophic cells of: condylar cartilage. The distribution of enzymô activity has been located in fracture callus biv Gothlin and Ericsson, ${ }^{21}$ Salomon, ${ }^{22}$ and Volpio et al. ${ }^{2.3}$ In all the above cases hypertrophy if chondrocytes is associated with increased alkaline phosphatase activity around the chondrocytes themE selves and associated matrix vesicles. This is the firso detailed ultrastructural localisation of alkaline phosphatase activity in osteoarthritic human articula cartilage. The presence of increased levels of alkalin phosphatase activity around chondrocytes and matri 
vesicles in the deep zone compared with normal cartilage is consistent with the suggestion that in osteoarthritis articular cartilage (considered by some to be a latent growth plate) has reverted to a growth phase. ${ }^{4} 27$ This could lead to an advance of the tidemark and subchondral bone. A reduction of the saggital depth of the cartilage or narrowing of the joint space in $x$ ray radiographs may be due to this comparatively rapid mineralisation and advance of the calcification front as suggested by Ali and Evans. ${ }^{4}$

An abnormal advance of the calcification front may make the subchondral region uneven and put greater stress on the remaining cartilage, which may become susceptible to degradation by normal wear processes. Such a pattern over a long period could degrade cartilage in the pressure bearing region. ${ }^{27} 32{ }^{33}$ Changes in local calcium concentration in this area could alter the physicochemical properties of the tissue $e^{34-36}$ and possibly disrupt the structure of the extracellular matrix as raised levels of calcium in vitro unfold collagen fibrils, and high levels of $\mathrm{CaCl}_{2}$ can extract proteoglycans from cartilage. ${ }^{37}$

We would like to thank Miss Tracey Harrod for typing the manuscript. We are grateful to the Arthritis and Rheumatism Council for their generous support.

\section{References}

1 Dieppe P A. Huskisson E C, Crocker P. Willoughby D A. Apatite deposition disease: a new arthropathy. Lancet 1976; i: 266-8.

2 Dieppe P A, Calvert P. Crystals and joint disease. London: Chapman and Hall, 1983.

3 Dieppe P A. Huskisson E C. Willoughby D A. The inflammatory component of osteoarthritis. In: Nuki G, ed. The aetiopathogenesis of osteoarthritis. Tunbridge Wells: Pitman Medical. 1984: 117-22.

4 Ali S Y. Evans L. Enzymatic degradation of cartilage in osteoarthritis. Fed Proc 1973; 32: 1494-8.

5 Ali S Y. Bayliss M T. Enzymic changes in human osteoarthritic cartilage. In: Ali S Y. Elves M W. Leaback D H. eds. Normal and osteoarthritic articular cartilage. London: Institute of Orthopaedics, 1974: 189-201.

6 Ali S Y, Griffiths S. New types of calcium phosphate crystals in arthritic cartilage. Semin Arthritis Rheum 1981; 11(suppl 1): 124-6.

7 Ali S Y, Griffiths S. Formation of calcium phosphate crystals in normal and osteoarthritic cartilage. Ann Rheum Dis 1983; 42(suppl 1): 45-8.

8 Ali S Y. Apatite-type crystal deposition in arthritic cartilage. Scanning Electron Microscopy 1985: 4: 1555-66.

9 Rees J A, Ali S Y, Mason A Z. Scanning electron microscopy and microanalysis of 'cuboid' crystals in human articular cartilage. In: Ali S Y, ed. Cell mediated calcification and matrix vesicles. Amsterdam: Elsevier, 1986: 365-71.

10 Ali S Y. Calcification of cartilage. In: Hall B K, ed. Cartilage structure and function. New York: Academic Press, 1983: 343-78.

11 Ali S Y, Sajdera S W, Anderson H C. Isolation and characterisation of calcifying matrix vesicles from epiphyseal cartilage. Proc Natl Acad Sci USA 1970; 67: 1513-20.

12 Robison $R$. The possible significance of hexosephosphoric esters in ossification. Biochem J 1923; 17: 286-93.

13 Gomori G. Calcification and phosphatase. Am J Pathol 1943; 19: 197-209.
14 Robinson R A, Doty S D. Cooper R R. Electron microscopy of mammalian bone. In: Zipkin I, ed. Biologicalmineralisation. New York: Wiley, 1973: 257-96.

15 Doty S B, Schofield B H. Enzyme histochemistry of bone and cartilage cells. Prog Histochem Cytochem 1976; 8: 1-37.

16 Orams H J, Snibson K J. Ultrastructural localisation and gradient of activity of alkaline phosphatase activity during rodent odontogenesis. Calcif Tissue Int 1982: 34: 273-9.

17 Matsuzawa T, Anderson H C. Phosphatase of epiphyseal cartilage studied by electron microscopic cytochemical methods. J Histochem Cytochem 1971; 19: 801-8.

18 Thyberg J, Friberg U. Electron microscopic enzyme histochemical studies on the cellular genesis of matrix vesicles in the epiphyseal plate. J Ultrastruct Res 1972; 41: 43-59.

19 Takagi M, Toda Y. Electron microscopic study of the intracellular activity of alkaline phosphatase in rat epiphyseal cartilage. J Electron Microsc (Tokyo) 1979; 28: 117-27.

20 Ralphs J R. Ali S Y. Histochemical localisation of alkaline phosphatase in rabbit distal ulnar growth plate. In: Ali S Y, ed. Cell mediated calcification and matrix vesicles. Amsterdam: Elsevier, 1986: 69-74.

21 Gothlin G, Ericsson J L E. Fine structural localisation of alkaline phosphomonoesterase in the fracture callus of the rat. Isr J Med Sci 1971; 7: 488-90.

22 Salomon C D. A fine structural study on the extracellular activity of alkaline phosphatase and its role in calcification. Calcified Tissue Research 1974; 15: 201-12.

23 Volpin G, Rees J A, Ali S Y, Bentley G. Distribution of alkaline phosphatase activity in experimentally produced callus in rats. J Bone Joint Surg [Br] 1986; 68: 629-34.

24 Meikle M C. The mineralisation of condylar cartilage in the rat mandible: an electron microscopic enzyme histochemical study. Arch Oral Biol 1976; 21: 33-43.

25 Lewinson D, Toister Z, Silbermann M. Quantitative and distributional changes in the activity of alkaline phosphatase during the maturation of cartilage. J Histochem Cytochem 1982; 30: 261-9.

26 Dmitrovsky E, Lane L B, Bullough P G. The characterisation of the tidemark in human articular cartilage. Metabolic Bone Disease and Related Research 1978; 1: 115-8.

27 Ali S Y. New knowledge of osteoarthrosis. J Clin Pathol [Suppl] (R Coll Pathol) 1978; 12: 191-9.

28 Anderson H C. Matrix vesicle calcification: review and update. In: Peck W A, ed. Bone and mineral research. Vol 3. Amsterdam: Elsevier, 1985: 109-49.

29 Wuthier R E. Mechanisms of matrix vesicle-mediated mineralisation. In: Ali S Y, ed. Cell mediated calcification and matrix vesicles. Amsterdam: Elsevier, 1986: 47-55.

30 Morris D C, Vaananen H K. Munoz P, Anderson H C. Light and electron microscopic immunolocalisation of alkaline phosphatase in bovine growth plate cartilage. In: Ali S Y, ed. Cell mediated calcification and matrix vesicles. Amsterdam: Elsevier, 1986 21-7.

31 Cecil R N A, Anderson H C. Freeze fracture studies of matrix vesicle calcification in epiphyseal growth plate. Metabolic Bone Disease and Related Research 1978; 1: 89-97.

32 Radin E L, Swann D A. Paul I L, McGrath P. Factors influencing articular cartilage wear in vitro. Arthritis Rheum 1982; 25: 974-80.

33 Bullough P G, Jagannath A. The morphology of the calcification front in articular cartilage. J Bone Joint Surg $[\mathrm{Br}]$ 1983; 65: 72-8.

34 Gersh I, Catchpole H R. The nature of ground substance of connective tissue. Perspect Biol Med 1960; 3: 282-319.

35 Sokoloff L. Elasticity of articular cartilage: effect of ions and viscous solutions. Science 1963; 141: 1055-7.

36 Maroudas A. Physicochemical properties of articular cartilage. In: Freeman M A R, ed. Adult articular cartilage. Tunbridge Wells: Pitman Medical, 1973: 215-91.

37 Anderson H C, Sajdera S W. The fine structure of bovine nasal cartilage. J Cell Biol 1971; 49: 650-63. 